\title{
A Brief Review on the Synthesis, Cytotoxixity, Bioavailability and Various Applications of Graphene Nanomaterials
}

\author{
Saurabh Savita $^{1 *}$, Upendra Kumar Sharma ${ }^{1}$, Priya Bhardwaj ${ }^{1}$ and Abha Mishra ${ }^{2}$
}

1“"Department of Pharmaceutics, Institute of Pharmacy, Bundelkhand University Jhansi - 284128, Uttar Pradesh, India

${ }^{2}$ Department of Medicinal Chemistry, NIPER, Bijnor Road Lucknow - 226002, Uttar Pradesh, India

DOI: $10.36347 /$ sajp.2020.v09i09.004

| Received: 06.09.2020 | Accepted: 13.09.2020 | Published: 17.09.2020

*Corresponding author: Mr. Saurabh Savita

Abstract

The physicochemical characteristics of graphene-based nanometrics are ideal for a variety of electronic, telecommunication, energy, and healthcare applications. Human and environmental exposure to graphenic nanomaterials increases due to the synthesis, characterization and mass processing of graphene as well as the growth of biomedical and consumer products based on graphene. Throughout this paper, we analyze the various available synthetic methods of graphic nanomaterials and discuss in-vitro and in-vivo mammalian cell-associated biological structure and toxicity of these nanomaterials. Different synthesis strategies were developed to generate the chemical and physical properties of graphene nanometries. As such their relationships with cells and organs also change. Literature published bio-structure and cytotoxicity results from graphene nanomaterials. In particular, graphene nanomaterials in in-vitro cell cultivation and animal models may contain toxic chemical residues, interfere with graphene cell interactions and complicate interpretation of the experimental results. Synthesis methods including exfoliation of the liquid phase and wet chemical oxidation require harmful organic solvents, surfactants, strong acids and oxidants to dissolve graphite flakes. Such biological and inorganic molecules, which interfere with living cells and tissues, activate toxins or eventually cause necrobiosis, can be deposited with the final graphene products. Residual chemicals in living cells pose a high risk of toxicity from graphene. This study summarizes the synthesis of nanomaterials, cytotoxicity, bioavailability, and various applications.

Keywords: Grapheme, Synthesis, Cell culture, Biocompatibility, Toxicity.

Copyright @ 2020: This is an open-access article distributed under the terms of the Creative Commons Attribution license which permits unrestricted use, distribution, and reproduction in any medium for non-commercial use (NonCommercial, or CC-BY-NC) provided the original author and source are credited.

\section{INTRODUCTION}

The carbon allotrops are graphite, diamond, carbon nanotube (CNT) and complementary. The most common allotropic graphite is madeup of hexagonally packed sp2 hybridized carbon sheets, stacked at a distance of $0.34 \mathrm{~nm}$ from the weak forces of Vander Waals. A graphene is the single graphite layer packed in a wave-filled crystal grid with one atomic-scale thickness. Boehm, Setton, and Stumpp coined the word graphene in 1994 [1].

In 2004, the University of Manchester research group Novoselov and Geim successfully exfoliated a single graphite layer using simple scotch tape methods. This single-level graph shows excellent intrinsic properties which led to the "Nobel Prize" for Physics in 2010 for Novoselov and Geim. Graphene is also a versatile building block for other carbohydrating structures, such as 0D compleerene, 1D carbon nanotube and 3D graphite, respectively. The two- dimensional graph has special physicochemical features [2-6]:

Graphene has become a multi-functional material for a broad variety of applications including sensors, solar cells, fuel panels, photocatalytics, supercapacitors, and batteries [7-11]

Nanotechnology is a multidisciplinary field of study covering a range of fields including biology, chemistry, electronics, materials, physics and medical sciences. Nanotechnology involves the design and production of new materials and devices by manipulating nanometer-scale material properties and functions. The biological, mechanical, physical and chemical behavior of these materials varies significantly from their bulk counterparts. Nanotechnology is very exciting to create and synthesize nanomaterials with different biological, physical, chemical and mechanical properties. Through the application of nanotechnology in the medical sector, scientists can create effective new 
materials and technologies for the exposure and obstacle of malignant diseases, advanced implants and highly bio-compatible artificial protheses. Carbon materials, such as carbon nanotubes and maps, have an outstanding module and mechanical efficiency, a high light transmission and excellent electrical conductivity [12]. This was supported by the use of this material for electrical apparatus, construction products, medical supplies, medical implants, etc. [13, 14]. For example, because of their hollow structure one dimensional (1D) carbon nanotubes (CNTs) promise drugs in biological cells. CNTs with needlelike features can penetrate easily into the plasma membrane and thus bear therapeutic molecules effectively. Cells penetrating nanotubes can, however, also damage organic cells because they cause significant toxicity and apoptosis [15]. Electron microscopic studies have revealed that nanotubes exist in cytoplasms, resulting in oxidative stress, reduced metabolic activity and subsequent cell death [17]. In this respect, the bio-distribution, the size, and shape of carbon nanotubes impede the application in the clinical area. This consists of simple building blocks, including GQD and Od bucky ball, 3D graphite, and 1D carbon nanotube for all other dimensional carbohydrates [18].

Graphene was first isolated by "Geim and Novoselov" through mechanical cleavage using a scotch tape to fix the flakes of graphite layers. Mechanically exfoliated, defect-free and pure graph surface, but very low in size. This application is limited mainly to work on the mechanical and optical properties of pure graphene. Researchers therefore performed several studies to synthesize graphic oxide (GO), reduced graphic oxide (RGO), and heat-reduced graphic oxide (TRG) to a wide degree. In the telecommunications, telecommunications and aeronautical industries, the outstanding electrical, mechanical and optical characteristics of the graphema sheets and of GQDs make this attractive [19-21].

Graphene, their derivative, and GQDs have provided promising materials for biomedical use such as tissue engineering, biosensors, bioimagery, pharmaceuticals, and photothermal therapy. GQDs are typically photoluminescent due to a quantum containing effect. The presence of GQDs $(<2 \mathrm{mg} / \mathrm{mL})$ that leads to the healthy development of zebras. When using graphene-based materials for biomedical applications, biocompatibility is a significant concern. Graphene and its derivatives are frequently inconsistent in their biocompatibility with literary works [22].

Chang et al., find that A549 (human basal epithelial basal cells) is not GO's and has no apparent cytotoxicity. However, GO appears to cause oxidative stress depending on the dose in cells, which decreases the cell viability to a high standard. Dose and size are related to these effects. Wang et al. GO also show dosedependent toxicity to human fibroblast cells and mice.
Tests showed that GOs of less than $20 \mathrm{~g} / \mathrm{mL}$ have no toxicity to human fibroblast cells. Natural cytotoxicity is observed at doses higher than $50 \mathrm{~g} / \mathrm{mL}$, including reduced cell adhesive and cell apoptosis. Small dose $(0.1 \mathrm{mg})$ and intermediate dose $(0.25 \mathrm{mg}) \mathrm{GO}$ in vivo mice experiments do not indicate any acute toxicity, but chronic toxicity is caused by a high-dose $(0.4 \mathrm{mg})$. Yang et al., researched in-vivo polyethylene glycol (PEG)-functional graphene biodistribution in mice. We have shown that PEGylated graphene is not significantly toxic in doses of $20 \mathrm{mg} / \mathrm{kg}$ for three months [23-28].

\section{THE STRUCTURE OF GRAPHENE Basics Structure}

Carbon is the sixth element in the Periodic Table with an electronic configuration of $1 \mathrm{~s} 22 \mathrm{~s} 22 \times 22 \mathrm{Py}$ $12 \mathrm{Py} 12 \mathrm{Pz} 0.2 \mathrm{pz}$ electron-free energy is kept for ease, even though it is equal to $2 \mathrm{px}$ and $2 \mathrm{py}$. Six electrons, four of which are electrons of interest, surround the nuclear carbon nucleus. These electrons are capable of forming three forms of carbon-valence hybridization: $\mathrm{sp}, \mathrm{sp} 2$, and sp3. Since carbon atoms share S2 electrons with their three carbon atoms, they form a planar wave structure, also called monolayer lines. During the typical sp2 hybridisation, the $\mu$ off-flane bond consists of $2 \mathrm{pz}$ orbital layers perpendicular to the planar structure of two adjacent carbon atoms. In contrast, the in-plane $\mu$ bond consists of the hybridized sp2 orbitals (2s,2px,2py). The resulting covalent, interatomically short bond, about $1.42 \AA$, which makes the bond even more potent than the hybridized carbon sp3 - carbon bonds in diamonds with an extensive mechanic function of monolayers, including a Young's 1 TPa module and a $130.5 \mathrm{GPa}$ tensile strength. With a semi filled $\alpha$-band, the steering band and valence band with a zero-band distance allow free moving electrons to be produced in the monolayer graph. In the $\mu$-bonds, the interaction between adjacent two-layer graphs and multi-layer graphs is also mild.

\section{Synthesis of Graphene-Based Nanomaterials}

Graphene can typically be synthesized up and down from both directions. The top-down route includes liquid exfoliation, micromechanical graphite cuttings, and the exfoliation of metallic graphite, accompanied by chemical or thermal RGO or TRG processes. The processing path from the bottom up involves the deposition of chemical vapor and $\mathrm{SiC}$ substratum epitaxial growth [29].

\section{Epitaxial Graphene on SiC Wafers}

Graphene films on $\mathrm{SiC}$ wafers can form at temperatures (usually more than 1000 C) by sublimating Si atoms from high vacuum wafers (UHV). As a result, graphene is left to the surface of the wafer. Nevertheless, small size SiC wafers, the high cost, and the need for UHV high-temperature equipment preclude this method from being used in commercial large-scale graphic production $[30,31]$. 


\section{Chemical Vapor Deposited Graphene Films}

A chemical vapor-deposit is usually used to produce great monocle graph films on transition metals (Fe, Ni, Co, Pt, Ru) by allowing a high-temperature film reaction chamber such as methane, ethane, or propane to be hydrated. $\mathrm{Cu}$ or $\mathrm{Ni}$ substrates are common because of their low cost for the decomposition of hydrocarbon gasses. Then the thin films are transferred to different substrates like $\mathrm{SiO}_{2} / \mathrm{Si}$, glass, or flexible polymer (PET). The graphics are processed in two steps and extended. The first step is the first carbon pyrolysis precursor. The development of dissociated carbon atoms follows the graphical structure creation. CVD graphene growth is typically achieved by a surface adsorption cycle in a $\mathrm{Cu}$ substratum with a low carbon solubility. The precursor of carbon breaks down and only adsorbs the metal surface, followed by migration and growth. Graphene on $\mathrm{Ni}$ is made from carbon segregation and precipitation, on the other hand. Carbon species are broken down and distributed over a high carbon metal surface at high temperatures to create a robust solution. The cooling increases carbon solubility and allows carbon atoms to move from the metal and graph on the $\mathrm{Ni}$ surface. Graphene foil growth and consistency can be affected by various factors, including material types and CVD parameters such as gas content of the precursor, concentration, flow rate, and temperature are measured. The graphene films of random graphene islands are high grain density polycrystalline. Such grain limits significantly degrade the electrical characteristics of graphic films as they serve as the electron dispersion core and reduce the mobility anticipated. Graphic films with small grains or even single crystal graphic films with lower grain borders must be created in this regard. In the past, $\mathrm{Xu}$ et al., developed single-crystal graphene $\left(5,50 \mathrm{~cm}^{2}\right)$, on the copper surface of the graphene islands, in a single meter $\mathrm{Cu}$ (111) foil and epitaxially. The as-synthesized graphemetric film had up to $23,000 \mathrm{~cm}^{2} \mathrm{~V}^{-1} \mathrm{~s}^{-1}$ mobility at $4 \mathrm{~K}$. For the development of bendable screens, displays and optoelectronic products, high graphic CVD-grown films are utilized [32-36].

\section{Liquid Phase Exfoliation}

Its low cost and simplicity make it a scalable route for mass graphene production. Graphite is dispersed between graph interlayers in a solvent in the absence or presence of surfactants. Ultrasound or shaving can promote graphite exfoliation in graph sheets. A purification step is taken to generate single, multi-faceted graph sheets. This technique allows exfoliated graph sheets to synthesize solvent suspension. Since graphene flakes' exfoliation and stability in the specific medium is dependent on organic solvents, surfactants, and strong acids, they can cause environmental pollution problems. Graphene sheets also have difficulty removing residual surfactants. Many organic solvents (e.g., N-methyl 2-pyrrolidone (NMP); $\mathrm{N}$, N-dimethyl-formamide (DMF); dichlorobenzene
(DCB) are highly toxic; cell toxicity induction may be possible, and cell manipulation should be avoided.

\section{Chemical and Thermal Reduction of GO'}

Graphene oxide is a derivative of graphene which is formed by the chemical oxidation of solid oxidants by graphite flocks. Using sulphuric acid, sodium nitrate, and potassium permanganate mixtures in a strong stirring or sounding cycle, Modified Hummers is used to produce GO. Suspension is saturated with water, and then added hydrogen peroxide to increase oxidation, followed by water rinse. The disadvantages are extended processing times and toxic gas output $\left(\mathrm{NO}_{2}\right.$ and $\left.\mathrm{N}_{2} \mathrm{O}_{4}\right)$. Tour and colleagues adapted this method to address these problems by replacing sodium nitrate with phosphoric acid in mixed $\mathrm{H}_{2} \mathrm{SO}_{4} / \mathrm{H}_{3} \mathrm{PO}_{4}$ ratio (9:1). This method's advantage is reducing toxic gas formation. The drawbacks include substantial $\mathrm{KMnO}_{4}$, boring sampling, filtration, centrifugation, and washing. Thus, several techniques were introduced to further alter the Hummers process, such as using $\mathrm{K} 2 \mathrm{FeO} 4$ as a effective oxidizing agent instead of $\mathrm{KMnO}_{4}$ and eliminating $\mathrm{NaNO}_{3}$ in $\mathrm{GO}$ preparation.

\section{Nanocomposites Graphene-Polymer}

Pure graphene has an exceptionally high elastic module of about $1 \mathrm{TPa}$ and a resistance of 130 GPa, excellent optical clearance of $97.7 \%$ and a good electric conductivity and mobility of $2,105 \mathrm{~cm}^{2} \mathrm{~V}^{-1} \mathrm{~s}^{-1}$. Graphene is an appealing filler material for nanocomposites 40 polymers. Through adding microor nanoscales fillers, the output of high-flexibility polymers can be optimized for various applications. Polymer composites inherit beneficial properties of their components and, in addition, polymers guard against mechanical damage to embedded fillers [37-41]. Because of their light weight, ease of manufacture and low costs, the conventional polymer composites are widely used in the biomedical and industrial sectors as structural components. Nonetheless, the desired biological, mechanical and physical behavior includes high-volume filler material $(30 \%)$. The properties of the polymer microcomposites are affected by large volume filler material. Graphene-based nanomaterials can be used at low loading loads to fill and reinforce polymers [42-47].

The GO element is still substantially higher than biopolymers, including polylactic acid (PLA) of about 2.7-3 GPa and 0.4 GPa (PCL). GO can be used to increase the mechanical performance, thermal stability, and biocompatibility of nanocomposites of GO / PLA and GO / PCL. The biocomposite polymer can be made in different ways, including mixing, melting, and electrospinning of solutions [48-50]. 


\section{CONCLUSION}

This study summarizes the synthesis, cytotoxicity, bioavailability and specific applications of nanomaterials. Graphene toxicity has been shown to rely on scale, shape, cleanness, post-processing stages, oxidation state, dispersion, functional groups, route and dose, and exposure time methods. Both studies raise the understanding of synthesis, cytotoxicity, biological health services adaptability and increased risks to human health. This approach opens new possibilities for biomedical applications in orthopedics for the development of advanced bone stabilizers, fabrics and implants. More safety should be tested and examined before clinical use to make sure that these polymer nanocomposites are biocompatible with human tissue.

\section{REFERENCES}

1. Boehm HP, Setton R, Stumpp E. Nomenclature and terminology of graphite intercalation compounds (IUPAC Recommendations 1994). Pure and Applied Chemistry. 1994 Jan 1;66(9):1893-901.

2. Zhu Y, Murali S, Cai W, Li X, Suk JW, Potts JR, Ruoff RS. Graphene and graphene oxide: synthesis, properties, and applications. Advanced materials. 2010 Sep 15;22(35):3906-24.

3. Du X, Skachko I, Barker A, Andrei EY. Approaching ballistic transport in suspended graphene. Nature nanotechnology. 2008 Aug;3(8):491-5.

4. Lee C, Wei X, Kysar JW, Hone J. Measurement of the elastic properties and intrinsic strength of monolayer graphene. science. 2008 Jul 18;321(5887):385-8.

5. Huang X, Yin Z, Wu S, Qi X, He Q, Zhang Q, Yan Q, Boey F, Zhang H. Graphene- based materials: synthesis, characterization, properties, and applications. small. $2011 \mathrm{Jul}$ 18;7(14):1876-902.

6. Balandin AA, Ghosh S, Bao W, Calizo I, Teweldebrhan D, Miao F, Lau CN. Superior thermal conductivity of single-layer graphene. Nano letters. 2008 Mar 12;8(3):902-7.

7. Stoller MD, Park S, Zhu Y, An J, Ruoff RS. Graphene-based ultracapacitors. Nano letters. 2008 Oct 8;8(10):3498-502.

8. Loh KP, Bao Q, Eda G, Chhowalla M. Graphene oxide as a chemically tunable platform for optical applications. Nature chemistry. 2010 Dec;2(12):1015.

9. Gomez De Arco L, Zhang Y, Schlenker CW, Ryu $\mathrm{K}$, Thompson ME, Zhou C. Continuous, highly flexible, and transparent graphene films by chemical vapor deposition for organic photovoltaics. ACS nano. 2010 May 25;4(5):286573.

10. Babu SG, Vinoth R, Kumar DP, Shankar MV, Chou HL, Vinodgopal K, Neppolian B. Influence of electron storing, transferring and shuttling assets of reduced graphene oxide at the interfacial copper doped $\mathrm{TiO} 2 \mathrm{p}-\mathrm{n}$ heterojunction for increased hydrogen production. Nanoscale. 2015;7(17):784957.

11. Mahmood N, Zhang C, Yin H, Hou Y. Graphenebased nanocomposites for energy storage and conversion in lithium batteries, supercapacitors and fuel cells. Journal of Materials Chemistry A. 2014;2(1):15-32.

12. Iijima S, Brabec C, Maiti A, Bernholc J. Structural flexibility of carbon nanotubes. J. Chem. Phys. 1998, 104, 2089-2092.

13. Shareena TP, McShan D, Dasmahapatra AK, Tchounwou PB. A review on graphene-based nanomaterials in biomedical applications and risks in environment and health. Nano-micro letters. 2018 Jul 1;10(3):53.

14. Liu C, Wong HM, Yeung KW, Tjong SC. Novel electrospun polylactic acid nanocomposite fiber mats with hybrid graphene oxide and nanohydroxyapatite reinforcements having enhanced biocompatibility. Polymers. 2016 Aug;8(8):287.

15. Tsukahara T, Matsuda $Y$, Haniu $H$. The role of autophagy as a mechanism of toxicity induced by multi-walled carbon nanotubes in human lung cells. International Journal of Molecular Sciences. 2015 Jan;16(1):40-8.

16. Cui X, Wan B, Yang Y, Ren X, Guo LH. Length effects on the dynamic process of cellular uptake and exocytosis of single-walled carbon nanotubes in murine macrophage cells. Scientific reports. 2017 May 10;7(1):1-3.

17. Shang S, Yang SY, Liu ZM, Yang X. Oxidative damage in the kidney and brain of mice induced by different nano-materials. Frontiers in biology. 2015 Feb 1;10(1):91-6.

18. Nakano H, Tetsuka H, Spencer MJ, Morishita T. Chemical modification of group IV graphene analogs. Science and Technology of advanced MaTerialS. 2018 Dec 31;19(1):76-100.

19. Lu YF, Lo ST, Lin JC, Zhang W, Lu JY, Liu FH, Tseng CM, Lee YH, Liang CT, Li LJ. Nitrogendoped graphene sheets grown by chemical vapor deposition: Synthesis and influence of nitrogen impurities on carrier transport. ACS nano. 2013 Aug 27;7(8):6522-32.

20. Some S, Kim J, Lee K, Kulkarni A, Yoon Y, Lee S, Kim T, Lee H. Highly air- stable phosphorusdoped n- type graphene field- effect transistors. Advanced materials. 2012 Oct 23;24(40):5481-6.

21. Park HY, Yoon JS, Jeon J, Kim J, Jo SH, Yu HY, Lee S, Park JH. Controllable and air-stable graphene n-type doping on phosphosilicate glass for intrinsic graphene. Organic Electronics. 2015 Jul 1;22:117-21.

22. Roy P, Periasamy AP, Chuang C, Liou YR, Chen YF, Joly J, Liang CT, Chang HT. Plant leafderived graphene quantum dots and applications for white LEDs. New Journal of Chemistry. 2014;38(10):4946-51. 
23. Lammel T, Boisseaux $\mathrm{P}$, Fernández-Cruz ML, Navas JM. Internalization and cytotoxicity of graphene oxide and carboxyl graphene nanoplatelets in the human hepatocellular carcinoma cell line Hep G2. Particle and fibre toxicology. 2013 Dec 1;10(1):27.

24. Bengtson S, Kling K, Madsen AM, Noergaard AW, Jacobsen NR, Clausen PA, Alonso B, Pesquera A, Zurutuza A, Ramos R, Okuno H. No cytotoxicity or genotoxicity of graphene and graphene oxide in murine lung epithelial FE1 cells in vitro. Environmental and molecular mutagenesis. 2016 Jul;57(6):469-82.

25. Liao KH, Lin YS, Macosko CW, Haynes CL. Cytotoxicity of graphene oxide and graphene in human erythrocytes and skin fibroblasts. ACS applied materials \& interfaces. 2011 Jul 27;3(7):2607-15.

26. Chang Y, Yang ST, Liu JH, Dong E, Wang Y, Cao A, Liu Y, Wang H. In vitro toxicity evaluation of graphene oxide on A549 cells. Toxicology letters. 2011 Feb 5;200(3):201-10.

27. Wang K, Ruan J, Song H, Zhang J, Wo Y, Guo S, Cui D. Biocompatibility of graphene oxide, Nanoscale Res. 2016.

28. Yang K, Wan J, Zhang S, Zhang Y, Lee ST, Liu Z. In vivo pharmacokinetics, long-term biodistribution, and toxicology of PEGylated graphene in mice. ACS nano. 2011 Jan 25;5(1):516-22.

29. Wang XY, Narita A, Müllen K. Precision synthesis versus bulk-scale fabrication of graphenes. Nature Reviews Chemistry. 2017 Dec 20;2(1):1-0.

30. Badami DV. X-ray studies of graphite formed by decomposing silicon carbide. Carbon. $1965 \mathrm{Jul}$ 1;3(1):53-7.

31. Norimatsu W, Kusunoki M. Epitaxial graphene on $\mathrm{SiC}\{0001\}$ : advances and perspectives. Physical Chemistry Chemical Physics. 2014;16(8):3501-11.

32. Reina A, Jia X, Ho J, Nezich D, Son H, Bulovic V, Dresselhaus MS, Kong J. Large area, few-layer graphene films on arbitrary substrates by chemical vapor deposition. Nano letters. 2009 Jan 14;9(1):30-5.

33. Li X, Cai W, An J, Kim S, Nah J, Yang D, Piner R, Velamakanni A, Jung I, Tutuc E, Banerjee SK. Large-area synthesis of high-quality and uniform graphene films on copper foils. science. 2009 Jun 5;324(5932):1312-4.

34. Li X, Cai W, Colombo L, Ruoff RS. Evolution of graphene growth on $\mathrm{Ni}$ and $\mathrm{Cu}$ by carbon isotope labeling. Nano letters. 2009 Dec 9;9(12):4268-72.

35. Li X, Magnuson CW, Venugopal A, An J, Suk JW, Han B, Borysiak M, Cai W, Velamakanni A, Zhu Y, Fu L. Graphene films with large domain size by a two-step chemical vapor deposition process. Nano letters. 2010 Nov 10;10(11):4328-34.

36. Xu X, Zhang Z, Dong J, Yi D, Niu J, Wu M, Lin L, Yin R, Li M, Zhou J, Wang S. Ultrafast epitaxial growth of metre-sized single-crystal graphene on industrial $\mathrm{Cu}$ foil. Science bulletin. $2017 \mathrm{Aug}$ 15;62(15):1074-80.

37. Guerrero-Contreras J, Caballero-Briones F. Graphene oxide powders with different oxidation degree, prepared by synthesis variations of the Hummers method. Materials Chemistry and Physics. 2015 Mar 1;153:209-20.

38. Marcano DC, Kosynkin DV, Berlin JM, Sinitskii A, Sun Z, Slesarev A, Alemany LB, Lu W, Tour JM. Improved synthesis of graphene oxide. ACS nano. 2010 Aug 24;4(8):4806-14.

39. Peng L, Xu Z, Liu Z, Wei Y, Sun H, Li Z, Zhao X, Gao C. An iron-based green approach to 1-h production of single-layer graphene oxide. Nature communications. 2015 Jan 21;6(1):1-9.

40. He L, Tjong SC. Facile synthesis of silverdecorated reduced graphene oxide as a hybrid filler material for electrically conductive polymer composites. RSC Advances. 2015;5(20):15070-6.

41. Tjong SC, Meng YZ. Preparation and characterization of melt- compounded polyethylene/vermiculite nanocomposites. Journal of Polymer Science Part B: Polymer Physics. 2003 Jul 1;41(13):1476-84.

42. Meng YZ, Tjong SC, Hay AS, Wang SJ. Synthesis and proton conductivities of phosphonic acid containing poly- (arylene ether) s. Journal of Polymer Science Part A: Polymer Chemistry. 2001 Oct 1;39(19):3218-26.

43. Meng YZ, Hay AA, Jian XG, Tjong SC. Synthesis and properties of poly (aryl ether sulfone) $\mathrm{s}$ containing the phthalazinone moiety. Journal of applied polymer science. 1998 Apr 4;68(1):137-43.

44. Tjong SC, Meng YZ. Morphology and mechanical characteristics of compatibilized polyamide 6liquid crystalline polymer composites. Polymer. 1997 Sep 1;38(18):4609-15.

45. Meng YZ, Tjong SC. Rheology and morphology of compatibilized polyamide 6 blends containing liquid crystalline copolyesters. Polymer. 1998 Jan 1;39(1):99-107.

46. Li RK, Liang JZ, Tjong SC. Morphology and dynamic mechanical properties of glass beads filled low density polyethylene composites. Journal of Materials Processing Technology. 1998 Jul 1;79(13):59-65.

47. Bonner M, Ward IM, McGregor W, Tanner KE, Bonfield W. Hydroxyapatite/polypropylene composite: a novel bone substitute material. Journal of materials science letters. 2001 Nov 1;20(22):2049-51.

48. Li W, Xu Z, Chen L, Shan M, Tian X, Yang C, Lv H, Qian X. A facile method to produce graphene oxide-g-poly (L-lactic acid) as an promising reinforcement for PLLA nanocomposites. Chemical Engineering Journal. 2014 Feb 1;237:291-9.

49. Bayer IS. Thermomechanical properties of polylactic acid-graphene composites: a state-of-the- 
art review for biomedical applications. Materials. 2017 Jul;10(7):748.

50. Arriagada P, Palza H, Palma P, Flores M, Caviedes P. Poly (lactic acid) composites based on graphene oxide particles with antibacterial behavior enhanced by electrical stimulus and biocompatibility. Journal of Biomedical Materials Research Part A. 2018 Apr;106(4):1051-60.

51. Zhang Y, Ali SF, Dervishi E, Xu Y, Li Z, Casciano D, Biris AS. Cytotoxicity effects of graphene and single-wall carbon nanotubes in neural phaeochromocytoma-derived PC12 cells. ACS nano. 2010 Jun 22;4(6):3181-6.

52. Vallabani NV, Mittal S, Shukla RK, Pandey AK, Dhakate SR, Pasricha R, Dhawan A. Toxicity of graphene in normal human lung cells (BEAS-2B). Journal of biomedical nanotechnology. 2011 Jan 1;7(1):106-7.

53. Yuan J, Gao H, Sui J, Duan H, Chen WN, Ching CB. Cytotoxicity evaluation of oxidized singlewalled carbon nanotubes and graphene oxide on human hepatoma HepG2 cells: an iTRAQ-coupled 2D LC-MS/MS proteome analysis. Toxicological Sciences. 2012 Mar 1;126(1):149-61.

54. Lv M, Zhang Y, Liang L, Wei M, Hu W, Li X, Huang Q. Effect of graphene oxide on undifferentiated and retinoic acid-differentiated SH-SY5Y cells line. Nanoscale. 2012;4(13):38616.

55. Talukdar Y, Rashkow JT, Lalwani G, Kanakia S, Sitharaman B. The effects of graphene nanostructures on mesenchymal stem cells. Biomaterials. 2014 Jun 1;35(18):4863-77.

56. Chng EL, Chua CK, Pumera M. Graphene oxide nanoribbons exhibit significantly greater toxicity than graphene oxide nanoplatelets. Nanoscale. 2014;6(18):10792-7.

57. Akhavan O, Ghaderi E, Emamy H, Akhavan F. Genotoxicity of graphene nanoribbons in human mesenchymal stem cells. Carbon. 2013 Apr 1;54:419-31.

58. Jaworski S, Sawosz E, Grodzik M, Winnicka A, Prasek M, Wierzbicki M, Chwalibog A. In vitro evaluation of the effects of graphene platelets on glioblastoma multiforme cells. International journal of nanomedicine. 2013;8:413.

59. Sasidharan A, Panchakarla LS, Chandran P, Menon D, Nair S, Rao CN, Koyakutty M. Differential nano-bio interactions and toxicity effects of pristine versus functionalized graphene. Nanoscale. 2011;3(6):2461-4.

60. Matesanz MC, Vila M, Feito MJ, Linares J, Gonçalves G, Vallet-Regi M, Marques PA, Portolés MT. The effects of graphene oxide nanosheets localized on F-actin filaments on cell- cycle alterations. Biomaterials. 2013 Feb 1;34(5):1562-9.

61. Yuan X, Liu Z, Guo Z, Ji Y, Jin M, Wang X. Cellular distribution and cytotoxicity of graphene quantum dots with different functional groups. Nanoscale research letters. 2014 Dec;9(1):1-9.

62. Horvath L, Magrez A, Burghard M, Kern K, Forro L, Schwaller B. Evaluation of the toxicity of graphene derivatives on cells of the lung luminal surface. Carbon. 2013 Nov 1;64:45-60.

63. Das S, Singh S, Singh V, Joung D, Dowding JM, Reid D, Anderson J, Zhai L, Khondaker SI, Self WT. Oxygenated functional group density on graphene oxide: its effect on cell toxicity. Particle \& Particle Systems Characterization. 2013; 30(2):148-157.

64. Chong Y, Ma Y, Shen H, Tu X, Zhou X, Xu J, Dai $\mathrm{J}$, Fan $\mathrm{S}$, Zhang $\mathrm{Z}$. The in vitro and in vivo toxicity of graphene quantum dots. Biomaterials. 2014; 35(19):5041-5048.

65. Mullick Chowdhury S, Lalwani G, Zhang K, Yang JY, Neville K, Sitharaman B. Cell specific cytotoxicity and uptake of graphene nanoribbons. Biomaterials. 2013; 34(1):283-293.

66. Akhavan O, Ghaderi E, Akhavan A. Sizedependent genotoxicity of graphene nanoplatelets in human stem cells. Biomaterials. 2012; 33(32):8017-8025.

67. Chang Y, Yang ST, Liu JH, Dong E, Wang Y, Cao A, Liu Y, Wang H. In vitro toxicity evaluation of graphene oxide on A549 cells. Toxicol Lett. 2011; 200(3):201-210.

68. Yue H, Wei W, Yue Z, Wang B, Luo N, Gao Y, $\mathrm{Ma} \mathrm{D}, \mathrm{Ma} \mathrm{G}, \mathrm{Su} \mathrm{Z}$. The role of the lateral dimension of graphene oxide in the regulation of cellular responses. Biomaterials. 2012; 33(16):4013-4021.

69. Zhi X, Fang H, Bao C, Shen G, Zhang J, Wang K, Guo S, Wan T, Cui D. The immunotoxicity of graphene oxides and the effect of PVP-coating. Biomaterials. 2013; 34(21):5254-5261.

70. Chen GY, Yang HJ, Lu CH, Chao YC, Hwang SM, Chen CL, Lo KW, Sung LY, Luo WY, Tuan HY, $\mathrm{Hu}$ YC. Simultaneous induction of autophagy and toll-like receptor signaling pathways by graphene oxide. Biomaterials. 2012; 33(27):6559-6569.

71. Liao KH, Lin YS, Macosko CW, Haynes CL. Cytotoxicity of graphene oxide and graphene in human erythrocytes and skin fibroblasts. ACS Appl Mater Interfaces. 2011; 3(7):2607-2615.

72. Singh SK, Singh MK, Nayak MK, Kumari S, Shrivastava S, Gracio JJ, Dash D. Thrombus inducing property of atomically thin graphene oxide sheets. ACS Nano. 2011; 5(6):4987-4996. 